\title{
Radiation therapy for stage IVA uterine cervical cancer: treatment outcomes including prognostic factors and risk of vesicovaginal and rectovaginal fistulas
}

\author{
Masaharu Hata1,2, Izumi Koike², Etsuko Miyagi,3, ${ }^{3}$,iko Numazaki ${ }^{4,5}$, Mikiko Asai- \\ Sato ${ }^{4}$, Hisashi Kaizu², Yuki Mukai², Shoko Takano², Eiko Ito², Madoka Sugiura² and \\ Tomio Inoue ${ }^{2}$ \\ ${ }^{1}$ Division of Radiation Oncology, Department of Oncology, Yokohama City University Graduate School of Medicine, Yokohama, \\ Kanagawa, Japan \\ ${ }^{2}$ Department of Radiology, Yokohama City University Graduate School of Medicine, Yokohama, Kanagawa, Japan \\ ${ }^{3}$ Division of Gynecologic Oncology, Department of Oncology, Yokohama City University Graduate School of Medicine, \\ Yokohama, Kanagawa, Japan \\ ${ }^{4}$ Department of Obstetrics and Gynecology, Yokohama City University Graduate School of Medicine, Yokohama, Kanagawa, Japan \\ ${ }^{5}$ Department of Obstetrics and Gynecology, Yokohama Minami Kyousai Hospital, Yokohama, Kanagawa, Japan
}

Correspondence to: Masaharu Hata, email: mhata@syd.odn.ne.jp

Keywords: cervical cancer; radiation therapy; stage IVA; uterine cervix; vesicovaginal fistula

Abbreviations: Biological effective dose, BED; high-dose-rate, HDR; computed tomography, CT; Radiation Therapy Oncology Group, RTOG

Received: September 11, $2017 \quad$ Accepted: October 27, $2017 \quad$ Published: December 01, 2017

Copyright: Hata et al. This is an open-access article distributed under the terms of the Creative Commons Attribution License 3.0 (CC BY $3.0)$, which permits unrestricted use, distribution, and reproduction in any medium, provided the original author and source are credited.

\section{ABSTRACT}

Purpose: To evaluate the safety and efficacy of radiation therapy for stage IVA uterine cervical cancer and to identify an optimal radiation regimen.

Results: Seventeen of the 28 patients developed recurrence after radiation therapy (local recurrence in 10 and distant metastasis in 12). The local control and distant metastasis-free rates at 3 years in all patients were $61 \%$ and $49 \%$, respectively. Fourteen patients died after radiation therapy, and all but 2 died of tumor progression. The disease-free, cause-specific, and overall survival rates at 3 years in all patients were $32 \%, 49 \%$, and $45 \%$, respectively, and the estimated median survival time was 32 months. Tumor size $(P=0.007)$ and involvement in the lower third of vagina $(P=$ 0.006) were significant prognostic factors for local control. Older age $(P=0.018)$ and performance status $(P=0.020)$ were significant prognostic factors for distant metastasis. The presence of hydronephrosis was the sole significant prognostic factor for survival $(P=0.026)$. Only 2 patients developed grade 3 late toxicities (vesicovaginal fistula and radiation proctitis, respectively).

Materials and Methods: Twenty-eight patients with stage IVA uterine cervical cancer received radiation therapy. All patients initially received external pelvic irradiation at a median dose of $\mathbf{5 0 . 4} \mathbf{~ G y}$ in $\mathbf{2 8}$ fractions. Twenty patients also received high-dose-rate intracavitary brachytherapy at a median dose of $22 \mathrm{~Gy}$ in 4 fractions. These fraction sizes were lower than conventional sizes. The total median dose for all 28 patients was $68.7 \mathrm{~Gy}$.

Conclusions: Radiation therapy is safe and effective for treatment of stage IVA uterine cervical cancer. The reduced radiation dose per fraction may contribute to the prevention of vesicovaginal fistula formation.

\section{INTRODUCTION}

Uterine cervical cancer is the fourth most common malignancy in women worldwide, following breast, colorectal, and lung cancers. An estimated 530,000 new cases and 270,000 deaths occur annually, accounting for $7.5 \%$ of all cancer-related deaths in female patients $[1,2]$. Around $85 \%$ of cases of uterine cervical cancer arise in 
less-developed countries, where it is the most common malignancy in women, accounting for almost $12 \%$ of all female cancers. Although screening for uterine cervical cancer and vaccination against human papilloma virus are becoming widespread, some patients still develop advanced uterine cervical cancer because of delayed detection. At diagnosis, about $3 \%$ of patients have stage IVA uterine cervical cancer with spread of the primary tumor into adjacent pelvic organs, such as the bladder and rectum, based on the International Federation of Gynecology and Obstetrics staging system [3, 4].

Patients with stage IVA uterine cervical cancer are inoperable but are candidates for curative radiation therapy. However, these patients have poorer tumor control and a worse prognosis than patients with tumors up to stage IIIB [4]. Few studies have reported the detailed outcomes of radiation therapy for stage IVA uterine cervical cancer, including its prognostic factors and risk of vesicovaginal and rectovaginal fistulas. We therefore retrospectively reviewed patients with stage IVA uterine cervical cancer treated with radiation therapy and herein discuss the treatment results and optimal radiation regimen.

\section{RESULTS}

\section{Tumor control}

In 26 of the 28 patients, the initial response to treatment was disappearance or marked reduction of the primary tumor, and the remaining 2 patients showed no change. The objective response rate was 93\%. However, 17 patients developed recurrence at a median time of 10 months (range, 1-52 months) after radiation therapy. Of these 17 patients, 10 had local recurrence in the pelvis within the radiation field (primary tumor progression in 9 and pelvic lymph node metastasis in 2), and 12 had distant metastases to the lung, liver, bone, and lymph nodes (such as the mediastinal and para-aortic lymph nodes situated outside the radiation field).

The local control and distant metastasis-free rates in all patients were $61 \%$ and $49 \%$, respectively, at 3 years (Figure 1).

\section{Survival}

Fourteen of the 28 patients died at 4-50 months (median, 15 months) after radiation therapy. Of these 14 patients, 12 died of tumor progression and the other 2 of cancer-unrelated causes. There was no mortality associated with treatment. The remaining 14 patients survived during a median follow-up of 45 months (range, 3-116 months) after radiation therapy.

The disease-free, cause-specific, and overall survival rates at 3 years in all patients were $32 \%, 49 \%$, and $45 \%$, respectively, and the estimated median survival time was 32 months (Figure 2).

\section{Evaluation of prognostic factors}

As shown in Table 1 , tumor size $(P=0.007)$ and involvement in the lower third of the vagina $(P=0.006)$ were significant prognostic factors for local control (Figure 3). Of 10 patients with involvement in the lower third of the vagina, 8 had bulky tumors $\geq 56$ $\mathrm{mm}$ in maximum diameter. Older age $(P=0.018)$ and performance status $(P=0.020)$ were significant prognostic factors for distant failure (Figure 4$)$. The presence of hydronephrosis was considered to be the sole significant prognostic factor for survival ( $P=0.026$, Figure 5).

\section{Toxicity}

There were no grade $\geq 3$ acute toxicities except for transient hematological reactions (Table 2). Grade 3 leukopenia, anemia, and thrombocytopenia developed in 2, 3, and 1 patient, respectively. All patients with grade 3 leukopenia and thrombocytopenia were treated with concurrent chemotherapy.

With respect to therapy-related late toxicities, 1 patient developed a grade 3 vesicovaginal fistula and 1 patient developed grade 3 radiation proctitis at 6 and 9 months after treatment, respectively. The patient with the vesicovaginal fistula had bladder invasion and received external irradiation plus intracavitary brachytherapy at a total dose of 131.9 Gy in the biological effective dose $\left(\mathrm{BED}_{3}, \alpha / \beta=3\right)$ without chemotherapy. The patient with radiation proctitis received a total dose of $152.6 \mathrm{~Gy}$ in $\mathrm{BED}_{3}$ without chemotherapy.

\section{DISCUSSION}

Although radiation therapy has been applied in patients with stage IVA uterine cervical cancer, the recurrence rate is high and patient survival is poor. In patients with stage IVA uterine cervical cancer, local recurrence is the most common cause of failure after radiation therapy, but good local control was achieved in the present study. The total median dose of 73.3 Gy in the 2 Gy per fraction-equivalent dose at point A was lower than the dose of $\geq 80$ Gy recommended by the American Brachytherapy Society for curative treatment of locally advanced cervical cancer [5]. However, it was close to the standard dose that has been widely used in Japan with good local control $[6,7]$. Consequently, the local control rate of $61 \%$ at 3 years in the present study was good compared with the rate of 39-59\% among patients with stage IVA uterine cervical cancer treated with radiation alone or chemoradiation in previous studies $[8,9]$.

Many patients with stage IVA disease had bulky tumors in the uterine cervix, with more than half the patients in this study having a cervical tumor of $>60 \mathrm{~mm}$ in diameter. Tumor size is an important variable affecting local control in patients at earlier stages. Landoni et al. 
Table 1: Results of Kaplan-Meier and univariate analyses of prognostic factors regarding local control, distant metastasis, and survival

\begin{tabular}{|c|c|c|c|c|c|c|c|}
\hline Variables & $\begin{array}{c}\text { No. of } \\
\text { patients }\end{array}$ & $\begin{array}{c}\text { 3-year local } \\
\text { control rates } \\
(\%)\end{array}$ & $P$ value & $\begin{array}{c}\text { 3-year distant } \\
\text { metastasis-free } \\
\text { rates }(\%)\end{array}$ & $P$ value & $\begin{array}{c}\text { 3-year overall } \\
\text { survival rates } \\
(\%)\end{array}$ & $P$ value \\
\hline \multicolumn{8}{|l|}{ Age (years) } \\
\hline$<72$ & 13 & 56 & 0.494 & 82 & 0.018 & 56 & 0.246 \\
\hline$\geq 72$ & 15 & 59 & & 16 & & 33 & \\
\hline \multicolumn{8}{|l|}{ Performance status } \\
\hline 0 & 8 & 88 & 0.360 & 88 & 0.020 & 63 & 0.204 \\
\hline 1 & 13 & 54 & & 48 & & 50 & \\
\hline $2-3$ & 7 & 0 & & 0 & & 0 & \\
\hline \multicolumn{8}{|l|}{ Histology } \\
\hline Squamous cell carcinoma & 25 & 65 & 0.224 & 44 & 0.176 & 47 & 0.740 \\
\hline Adenocarcinoma & 3 & 33 & & 100 & & 33 & \\
\hline \multicolumn{8}{|l|}{ Primary tumor size (mm) } \\
\hline$<56$ & 10 & 100 & 0.007 & 54 & 0.977 & 69 & 0.197 \\
\hline$\geq 56$ & 18 & 37 & & 48 & & 28 & \\
\hline \multicolumn{8}{|l|}{ Organ infiltration } \\
\hline Bladder alone & 24 & 65 & 0.571 & 47 & 0.968 & 45 & 0.881 \\
\hline Rectum alone or bladder and rectum & 4 & 38 & & 67 & & 38 & \\
\hline \multicolumn{8}{|l|}{ Pelvic wall infiltration } \\
\hline Bilateral & 13 & 45 & 0.293 & 25 & 0.368 & 26 & 0.088 \\
\hline Unilateral or none & 15 & 70 & & 60 & & 61 & \\
\hline \multicolumn{8}{|l|}{ Involvement in lower third of the vagina } \\
\hline Yes & 10 & 21 & 0.006 & 0 & 0.228 & 17 & 0.092 \\
\hline No & 18 & 81 & & 65 & & 57 & \\
\hline \multicolumn{8}{|l|}{ Hydronephrosis } \\
\hline Yes & 12 & 56 & 0.127 & 24 & 0.072 & 24 & 0.026 \\
\hline No & 16 & 68 & & 62 & & 61 & \\
\hline \multicolumn{8}{|l|}{ Hydrometra } \\
\hline Yes & 12 & 75 & 0.231 & 56 & 0.215 & 63 & 0.092 \\
\hline No & 16 & 45 & & 42 & & 31 & \\
\hline \multicolumn{8}{|l|}{ Pelvic lymph node metastasis } \\
\hline Yes & 12 & 58 & 0.540 & 57 & 0.592 & 36 & 0.935 \\
\hline No & 16 & 60 & & 44 & & 52 & \\
\hline \multicolumn{8}{|l|}{ Pretreatment hemoglobin value $(\mathrm{g} / \mathrm{dL})$} \\
\hline$<11.2$ & 13 & 64 & 0.982 & 43 & 0.331 & 34 & 0.284 \\
\hline$\geq 11.2$ & 14 & 57 & & 50 & & 50 & \\
\hline \multicolumn{8}{|c|}{ Pretreatment serum SCC antigen value $(\mathrm{ng} / \mathrm{mL})^{\mathrm{a}}$} \\
\hline$<16.8$ & 12 & 58 & 0.784 & 46 & 0.927 & 37 & 0.573 \\
\hline$\geq 16.8$ & 12 & 67 & & 38 & & 50 & \\
\hline \multicolumn{8}{|l|}{ Total radiation dose $\left(\mathrm{BED}_{10}, \mathrm{~Gy}\right)$} \\
\hline$<88.0$ & 14 & 63 & 0.347 & 68 & 0.608 & 44 & 0.382 \\
\hline$\geq 88.0$ & 14 & 65 & & 42 & & 50 & \\
\hline \multicolumn{8}{|l|}{ Concurrent chemotherapy } \\
\hline Yes & 6 & 75 & 0.336 & 83 & 0.105 & 63 & 0.302 \\
\hline No & 22 & 56 & & 37 & & 40 & \\
\hline
\end{tabular}

Abbreviations: SCC, squamous cell carcinoma; $\mathrm{BED}_{10}$, biological effective dose $(\alpha / \beta=10)$.

${ }^{a}$ Three patients with adenocarcinoma were excluded from this evaluation. 
carried out a randomized controlled trial involving 343 patients with stage IB-IIA uterine cervical cancer treated with surgery or radiation therapy [10]. In 167 patients treated with radiation therapy, patients with tumors of $\geq$ $4 \mathrm{~cm}$ in diameter had a $>2$-fold higher local recurrence rate than patients with tumors of $<4 \mathrm{~cm}(30 \%$ vs. $11 \%$, respectively) at median follow-up of 87 months. Similar results have been shown in many previous retrospective studies, and tumor size is an important and useful predictive variable for local control [11-13]. However, few studies have investigated whether tumor size affects local control in radiation therapy for stage IVA uterine cervical cancer alone. In the present study, tumor size was a significant prognostic factor for local control. Tumor size may be significant in stage IVA cancer as well as earlier stage cancer. Some authors have suggested that rectal invasion and the radiation dose to the cervical tumor are prognostic factors for local control, but neither was significant in our study $[8,9]$. These outcomes may have been obtained because compared with previous studies, the number of patients with rectal invasion was smaller and almost-curative radiation doses were delivered to more patients in the present study.

Distant metastasis after treatment is also a failure pattern found commonly in patients with stage IIB-IVA cancer, with a high rate of $18-39 \%[14,15]$. The data on distant failure in only patients with stage IVA cancer are limited, and an accurate rate is not known; however, Fagundes et al. reported an extremely high rate of $75 \%$ [16]. In the present study, the distant failure rate reached
$51 \%$ at 3 years after treatment. The poor prognosis of patients with stage IVA disease results from the high incidence of distant failure as well as poor local control. Some previously published reports, including ours, showed that tumor size was a significant prognostic factor for distant metastasis in patients with stage IB-IVA disease $[11,12,17]$. However, tumor size was not significant in this study. Rather, age and performance status were useful variables for prediction of distant failure. The influence of these variables on survival remains unknown.

Survival of patients with stage IVA uterine cervical cancer is poor, and in previous studies involving patients treated with radiation therapy with or without chemotherapy, the overall survival rates at 3 years were $18-44 \%$ [4, 8, 18-20]. Several studies have proved that concurrent use of chemotherapy, particularly platinumbased, with radiation therapy prolonged survival in patients with stage IB-IVA uterine cervical cancer compared with radiation therapy alone [21-23]. Furthermore, the use of consolidation chemotherapy following chemoradiotherapy in an attempt to improve patient survival was recently reported [23, 24]. However, a greater benefit of concurrent chemotherapy was seen in patients at an earlier stage, with $10 \%$ improvement in the survival rate at 5 years for patients with stage IB-IIA cancer, 7\% for stage IIB, and $3 \%$ for stage III-IVA [23]. The benefit of prolonged survival is thus small for patients with stage IVA disease. In addition, intensive treatment can provide enhanced efficacy but may increase the incidence of severe adverse events, such as vesicovaginal and rectovaginal fistulas, in

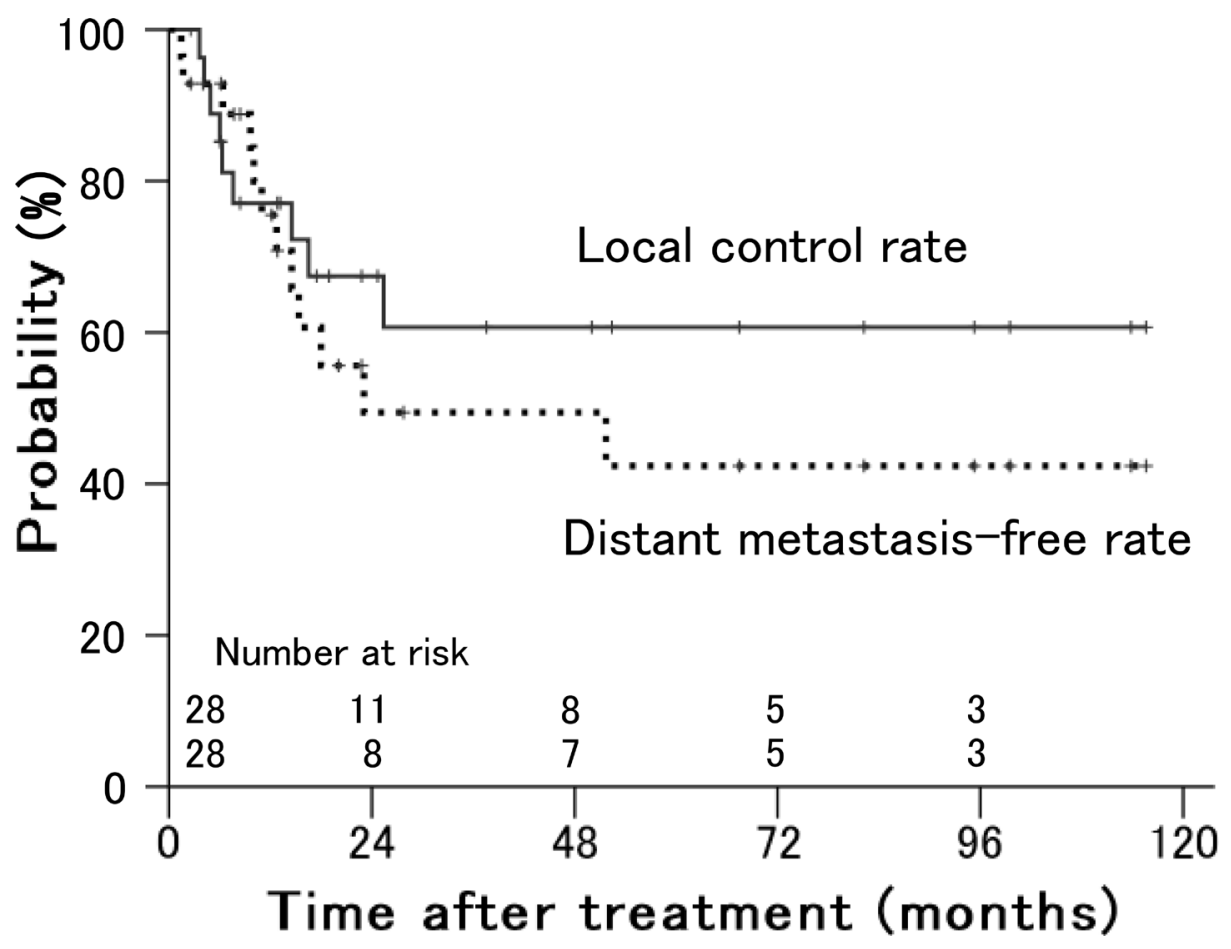

Figure 1: Local control and distant metastasis-free rates in patients with stage IVA uterine cervical cancer treated with radiation therapy. 
Table 2: Number of patients with therapy-related acute toxicities according to the RTOG acute radiation morbidity scoring criteria

\begin{tabular}{|c|c|c|c|c|}
\hline \multirow[b]{2}{*}{ Toxicity } & \multicolumn{4}{|c|}{ Grade } \\
\hline & 1 & 2 & 3 & 4 \\
\hline \multicolumn{5}{|l|}{ Hematologic } \\
\hline Leukopenia & 8 & 4 & 2 & 0 \\
\hline Anemia & 8 & 12 & 3 & 0 \\
\hline Thrombocytopenia & 2 & 1 & 1 & 0 \\
\hline \multicolumn{5}{|l|}{ Skin } \\
\hline $\begin{array}{l}\text { Erythema/moist } \\
\text { desquamation }\end{array}$ & 3 & 3 & 0 & 0 \\
\hline \multicolumn{5}{|l|}{ Upper G.I. } \\
\hline $\begin{array}{l}\text { Abdominal discomfort/ } \\
\text { nausea/vomiting }\end{array}$ & 6 & 3 & 0 & 0 \\
\hline \multicolumn{5}{|l|}{ Lower G.I. } \\
\hline Diarrhea & 11 & 1 & 0 & 0 \\
\hline \multicolumn{5}{|l|}{ Genitourinary } \\
\hline $\begin{array}{l}\text { Frequency of urination/ } \\
\text { dysuria/urgency }\end{array}$ & 4 & 1 & 0 & 0 \\
\hline
\end{tabular}

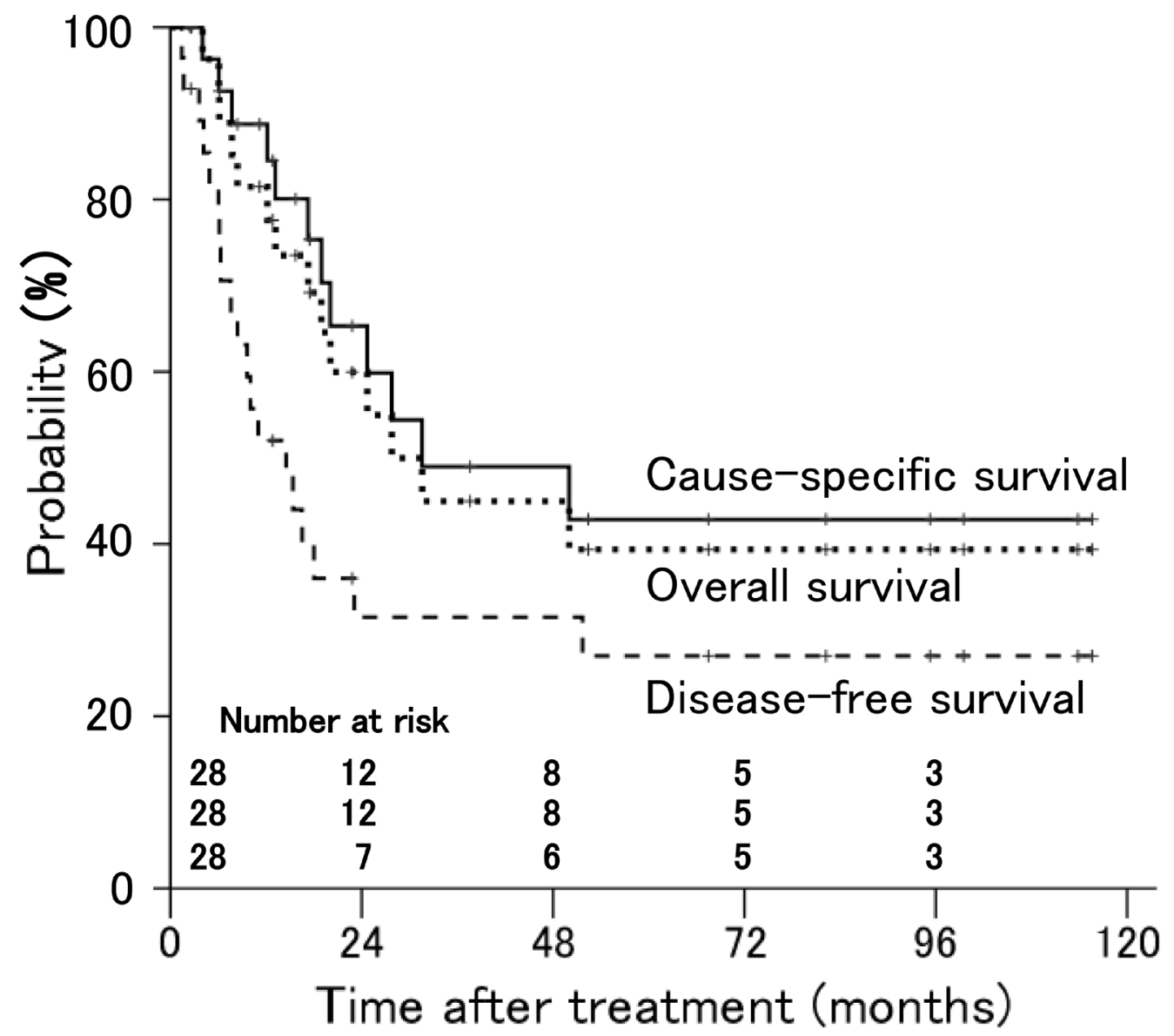

Figure 2: Disease-free, cause-specific, and overall survival rates in patients with stage IVA uterine cervical cancer treated with radiation therapy. 
patients with tumor invasion into the bladder and rectum, respectively. In the present study, almost $80 \%$ of patients were medically incapable of receiving chemotherapy because of renal dysfunction or old age. However, the overall survival time of $45 \%$ at 3 years in our study was more favorable than in previous studies. As a prognostic factor for survival, only the presence of hydronephrosis was significant. Patients with hydronephrosis were likely to develop distant metastasis after treatment, although it was only marginally significant, and this more distant spread may have resulted in poorer survival of patients with hydronephrosis. Previously published data on survival in only patients with stage IVA cancer are also limited. Wakatsuki et al. reported that hydronephrosis was a significant variable for worse survival in patients with stage IVA cancer after definitive radiation therapy: the 2-year disease-free survival rate was $7 \%$ in patients with hydronephrosis and $29 \%$ in patients without hydronephrosis [8]. The presence of rectal invasion or pelvic lymph node metastasis, the total radiation dose to cervical tumors, and age have also been suggested as predictors of survival by some authors, but none of them was significant in our study $[8,9,18]$.

In this study, all therapy-related acute toxicities were temporary and easily manageable. With the exception of hematological reactions, there were no grade $\geq 3$ adverse events. All 3 patients with grade 3 leukopenia or thrombocytopenia underwent concurrent chemotherapy. No patients developed grade $\geq 4$ acute toxicities. The concurrent use of chemotherapy with radiation therapy in the treatment of cervical cancer has been reported to significantly increase therapy-related acute toxicities, particularly hematological and gastrointestinal reactions $[23,25,26]$. The mild and negligible acute toxicities in the present study probably occurred because many

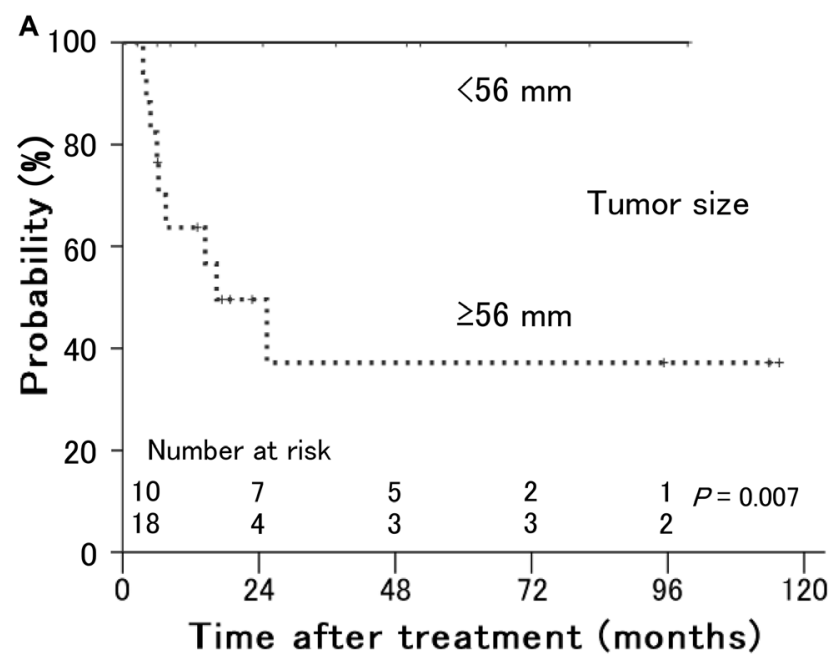

patients were treated with radiation therapy alone without chemotherapy.

Concerning late adverse events, vesicovaginal fistula formation following radiation therapy is uncommon in patients with cervical tumors without bladder invasion. However, it is a major issue in patients with bladder invasion and reportedly has a high incidence after curative radiation therapy. Biewenga et al. treated 20 patients with stage IVA cancer with bladder invasion using external pelvic irradiation at 46.0-50.4 Gy in 1.8-2.0 Gy fractions and brachytherapy at 20 Gy in 20 hours at a medium dose rate or $24 \mathrm{~Gy}$ at a high dose rate (24). Some patients also received concurrent chemotherapy with cisplatin and/or hyperthermia. Of these 20 patients, 3 (15\%) had vesicovaginal fistulas within 25 months after treatment. Moore et al. reported vesicovaginal fistula formation in 23 patients with stage IVA cancer with bladder invasion [27]. These 23 patients included 7 treated with radiation therapy alone; 14 treated with concurrent chemotherapy with cisplatin, paclitaxel, and/or 5-fluorouracil and radiation therapy; and 2 who received no treatment. External pelvic irradiation with a dose of 50.4 Gy in 28 fractions and lowdose-rate or high-dose-rate (HDR) brachytherapy were used for radiation therapy. Of the 23 patients, 11 (48\%) developed vesicovaginal fistulas during a median follow-up period of 19 months. There was no significant difference in vesicovaginal fistula formation between the 2 groups with or without chemotherapy.

In our study, only $1(3 \%)$ of the 26 patients with bladder invasion developed a vesicovaginal fistula. This incidence of vesicovaginal fistula was exceedingly lower than that in the study by Moore et al., in which 11 $(48 \%)$ of the 23 patients with bladder invasion developed vesicovaginal fistulas. Whether the use of chemotherapy with radiation therapy increases the risk of vesicovaginal

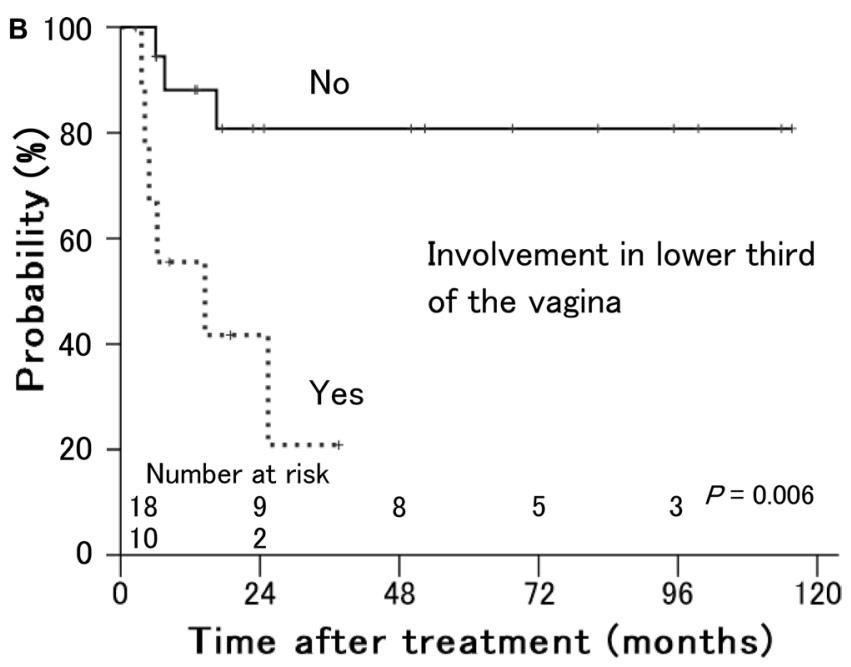

Figure 3: Local control rates in patients with stage IVA uterine cervical cancer treated with radiation therapy according to (A) primary tumor size and (B) involvement in the lower third of the vagina. Patients with smaller tumors and no involvement in the lower third of the vagina showed better local control. 
fistula formation remains unknown because of poor data. Generally, in the treatment of uterine cervical cancer, chemoradiation increases acute but not late toxicities compared with radiation alone [23, 25, 26]. However, in patients with bladder invasion, vesicovaginal fistula formation can be considered not a therapy-related toxicity but rather the result of effective treatment because of disappearance of the invasive tumor into the bladder wall. Therefore, the rapid reduction in tumor volume that results from intensive treatment may increase the risk of vesicovaginal fistula formation. This suggests that the concurrent use of chemotherapy with radiation therapy should be avoided for patients with bladder invasion. At the same time, however, the absence of chemotherapy may decrease the tumor control and cure rates. Therefore, whether concurrent chemotherapy should be avoided in the treatment of patients with bladder invasion currently remains unclear.

Patients with esophageal cancer characterized by T4 tumors with invasion into an adjacent structure frequently develop esophageal fistulas at a high rate of 10-29\% following concurrent chemoradiotherapy [28, 29]. A recent report indicated that in the treatment of patients with T4 esophageal cancer, induction chemotherapy followed by chemoradiotherapy reduced the incidence of esophageal fistula to only $5 \%$ [30]. This result cannot be identically applied to patients with bladder invasion of uterine cervical cancer, but slow reduction in the tumor volume can be hypothesized to decrease the risk of fistula formation.

Both fraction sizes used in the present study (1.8 Gy for external pelvic irradiation and 5 Gy for HDR intracavitary brachytherapy) used mostly in the present study were lower than the conventionally and widely used 2 Gy and 6 Gy, respectively. This suggests that a lower radiation dose per fraction may contribute to a decreased incidence of vesicovaginal fistula formation.

The frequency of rectal invasion of uterine cervical cancer is lower than that of bladder invasion; patients with rectal invasion account for only $4-21 \%$ of all patients

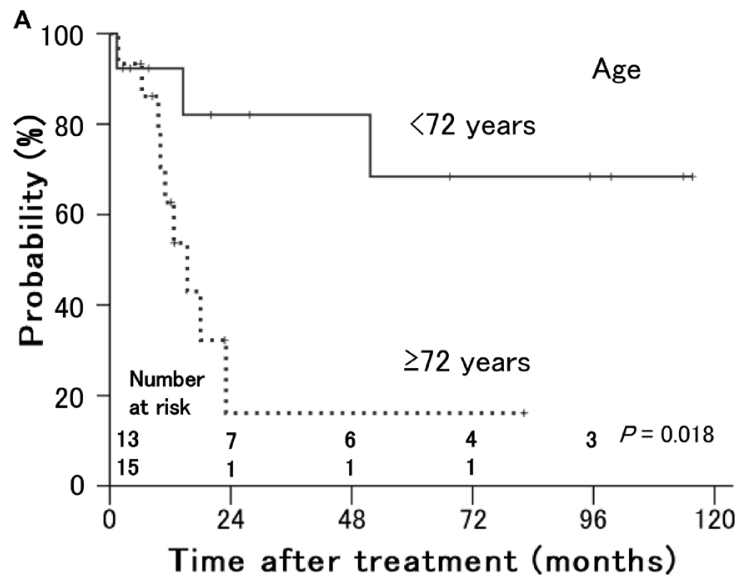

with stage IVA cancer [8, 9, 19, 20, 27]. In our study, only 4 patients $(14 \%)$ had rectal invasion. Therefore, reports of rectovaginal fistula formation are limited, and the treatment risk remains unknown. Nevertheless, a few studies involving a small number of patients have been performed, and the authors reported that almost none of the patients with rectal invasion developed a rectovaginal fistula following radiation therapy $[8,9,20$, 27]. Similarly, none of the patients in the present study developed a rectovaginal fistula. These results suggest that the incidence of rectovaginal fistula may actually be low. In addition, only 1 patient ( $3 \%$ ) developed grade 3 radiation proctitis as a late gastrointestinal adverse event. Grade $\geq 3$ gastrointestinal toxicities, including radiation proctitis, occurred in 5-14\% of patients with locally advanced cervical cancer treated with radiation therapy in some previous studies $[8,9,14,25]$. The severe late gastrointestinal toxicity seen in the present study also occurred at a lower incidence than in previous studies.

The present study has some limitations. Selection bias was unavoidable because the study involved a retrospective review. In addition, the number of patients was small and the follow-up period was short because it was a single-institutional study involving only patients with stage IVA uterine cervical cancer, which generally has a poor prognosis. However, considering the fact that very few data on stage IVA cervical cancer are currently available, we believe that the information obtained from this study will be useful for daily medical practice and future prospective studies.

In conclusion, radiation therapy is safe and effective in patients with stage IVA uterine cervical cancer. Uterine cervical cancer is sufficiently curable, even at stage IVA, and aggressive treatment should be considered. However, severe adverse events, such as vesicovaginal fistula formation, are the major issues after treatment. A radiation regimen with a lower dose fraction may decrease the risk of these complications. Further investigations involving larger numbers of patients and longer follow-up periods

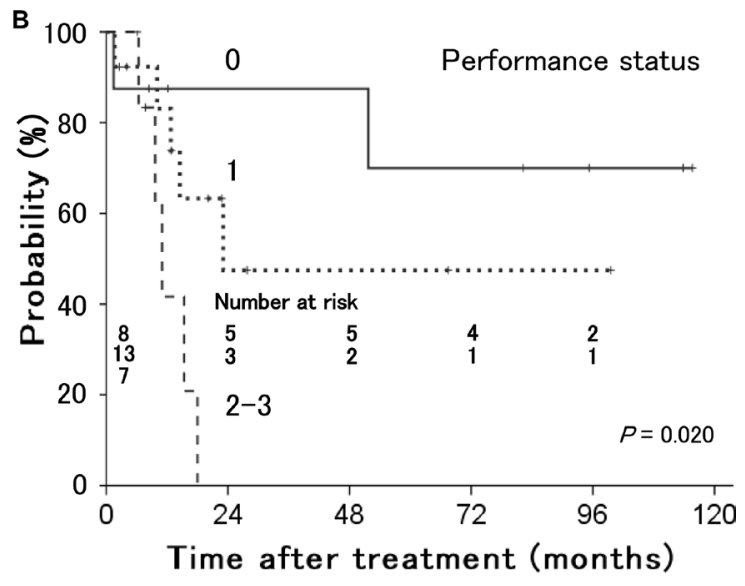

Figure 4: Distant metastasis-free rates in patients with stage IVA uterine cervical cancer treated with radiation therapy according to (A) age and (B) performance status. Younger patients and patients with a better performance status had a lower incidence of distant metastasis. 
are required to determine the optimal radiation regimen, with or without chemotherapy, for the treatment of patients with stage IVA uterine cervical cancer.

\section{MATERIALS AND METHODS}

\section{Patients}

From March 1995 to August 2013, a total of 28 patients with stage IVA uterine cervical cancer received radiation therapy with curative intent at our institution. All patients had histopathologically confirmed uterine cervical carcinoma and tumor invasion into the bladder and/or rectum. Bladder and rectal invasion was ascertained by cystoscopy and colonoscopy, respectively. Clinical stage was assessed by chest X-ray and computed tomography (CT), abdominal CT, and pelvic CT and/or magnetic resonance imaging prior to radiation therapy. Of the 28 patients, 12 had pelvic lymph node metastases but none had distant metastasis. Lymph node enlargement of $>10$ $\mathrm{mm}$ in the short axis on CT was defined as metastasis. Consequently, all patients were clinically diagnosed with stage IVA based on the TNM classification defined by the Union for International Cancer Control [31].
Patient characteristics are shown in Table 3. Informed consent was obtained from all patients before treatment. This study was approved by the institutional review board of our institution.

\section{Radiation therapy}

All 28 patients initially received external irradiation to the whole pelvis in antero-posterior opposed fields or antero-posterior and bilateral fields (box fields) with 10-15-MV X-rays. Patients received 1.8 Gy per day, 5 times per week, to a total dose of 45.0 50.4 Gy (median, 50.4 Gy) in 25-28 fractions (median, 28 fractions). Twenty of the 28 patients also received HDR intracavitary brachytherapy along with external irradiation to treat the primary cervical tumors. Total doses of 5-29 Gy (median, 22 Gy) in 1-5 once-weekly fractions (median, 4 fractions) of 3.5-6.0 Gy (median, 5 Gy) were delivered to point A using an HDR Ir-192 source [32]. Although intracavitary brachytherapy was considered for the control of primary tumors with higher doses in all patients, it was abandoned in the remaining 8 patients because of dementia, patient refusal or technical difficulties. The primary tumors in these 8 patients were

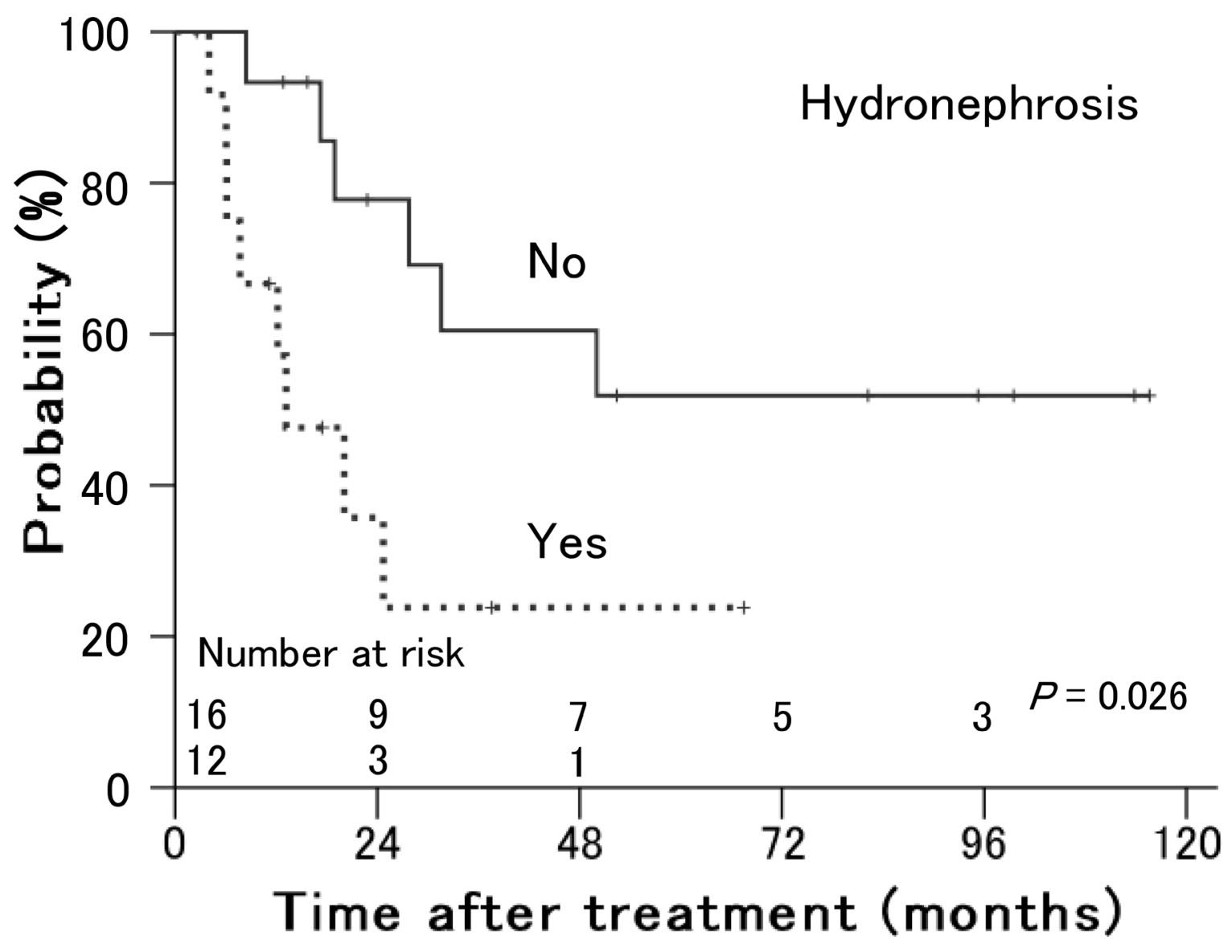

Figure 5: Overall survival rates in patients with stage IVA uterine cervical cancer treated with radiation therapy according to the presence of hydronephrosis. Patients without hydronephrosis showed better survival than patients with hydronephrosis. 
Table 3: Patient and tumor characteristics

\begin{tabular}{|c|c|}
\hline Number of patients & 28 \\
\hline Age (years) & $72(29-92)$ \\
\hline \multicolumn{2}{|l|}{ Performance status (ECOG) } \\
\hline 0 & $8(29)$ \\
\hline 1 & $13(46)$ \\
\hline 2 & $4(14)$ \\
\hline 3 & $3(11)$ \\
\hline \multicolumn{2}{|l|}{ Histology } \\
\hline Squamous cell carcinoma & $25(89)$ \\
\hline Adenocarcinoma & $3(11)$ \\
\hline Primary tumor size (maximum diameter, mm) & $61(45-110)$ \\
\hline \multicolumn{2}{|l|}{ Organ infiltration } \\
\hline Bladder alone & $24(86)$ \\
\hline Rectum alone & $2(7)$ \\
\hline Bladder and rectum & $2(7)$ \\
\hline \multicolumn{2}{|l|}{ Parametrial infiltration } \\
\hline Bilateral & $27(96)$ \\
\hline Unilateral & $1(4)$ \\
\hline \multicolumn{2}{|l|}{ Pelvic wall infiltration } \\
\hline Bilateral & $13(46)$ \\
\hline Unilateral & $13(46)$ \\
\hline None & $2(7)$ \\
\hline \multicolumn{2}{|l|}{ Involvement in the vagina } \\
\hline Lower third of the vagina & $10(36)$ \\
\hline Upper two-thirds of the vagina & $15(54)$ \\
\hline None & $3(11)$ \\
\hline \multicolumn{2}{|l|}{ Hydronephrosis } \\
\hline Yes & $12(43)$ \\
\hline No & $16(57)$ \\
\hline \multicolumn{2}{|l|}{ Hydrometra } \\
\hline Yes & $12(43)$ \\
\hline No & $16(57)$ \\
\hline \multicolumn{2}{|l|}{ Pelvic lymph node metastasis } \\
\hline Yes & $12(43)$ \\
\hline No & $16(57)$ \\
\hline Pretreatment hemoglobin value (g/dL) & $7.6-14.0(11.2)$ \\
\hline Pretreatment serum SCC antigen value (ng/mL) & $1.1-156.3(16.8)$ \\
\hline Total radiation dose $\left(\mathrm{BED}_{10}, \mathrm{~Gy}\right)$ & $59.5-105.4(88.0)$ \\
\hline \multicolumn{2}{|l|}{ Concurrent chemotherapy } \\
\hline Yes & $6(21)$ \\
\hline No & $22(79)$ \\
\hline
\end{tabular}

Data are presented at $n(\%)$ or median (range).

Abbreviations: ECOG, Eastern Cooperative Oncology Group; SCC, squamous cell carcinoma; BED 10 , biological effective dose $(\alpha / \beta=10)$. 
treated with external irradiation alone to total doses of 50.4-59.4 Gy in 28-33 fractions, consisting of whole pelvic irradiation of 45.0-50.4 Gy and a local radiation boost of 0-14.4 Gy. The total doses administered to all 28 patients were thus 50.4-79.4 Gy (median, 68.7 Gy), and the overall treatment time was 44-72 days (median, 51 days). The biological effective dose (BED) was calculated from the total physical dose according to the linear quadratic model using $\alpha / \beta$ ratios of 10 and 3 for early and late responding tissues, respectively. The median $\mathrm{BED}_{10}$ and $\mathrm{BED}_{3}$ were 88.0 Gy (range, 59.5-105.4 Gy) and 131.0 Gy (range, 80.6-166.0 Gy), respectively [33]. The $\mathrm{BED}_{10}$ was also considered as the dose of radiation that was effective for tumor treatment, and the median dose of 88.0 Gy corresponded to $73.3 \mathrm{~Gy}$ (range, 49.6-87.8 Gy) in the 2 Gy per fraction-equivalent dose.

\section{Chemotherapy}

Six of the 28 patients also received concurrent chemotherapy. These patients received 1-5 courses of mainly weekly intravenous cisplatin $\left(40 \mathrm{mg} / \mathrm{m}^{2}\right)$ during radiation therapy. For the remaining 22 patients, chemotherapy was unacceptable because of renal dysfunction or old age.

\section{Follow-up and evaluation criteria}

Patients were examined by pelvic CT within 1 month after completion of irradiation, and underwent subsequent follow-up CT scans at 3-12-month intervals. When the irradiated tumors show no progression, they were considered locally controlled.

Acute and late toxicities associated with radiation therapy were evaluated using the Radiation Therapy Oncology Group (RTOG) acute radiation morbidity scoring criteria and the RTOG/European Organization for Research and Treatment of Cancer late radiation morbidity scoring scheme, respectively [34]. Acute and late toxicities were defined as radiation-induced toxicities occurring within and after the first 3 months of beginning radiation therapy, respectively.

\section{Statistical analysis}

Actuarial survival and disease-control rates were calculated from the beginning of radiation therapy, according to the Kaplan-Meier method [35]. The logrank test was applied to detect probable prognostic factors considered predictable among various patient and tumor factors in the univariate analyses. A $P$ value of $<0.05$ was considered statistically significant. All statistical analyses were performed using the statistical software IBM SPSS version 22 (IBM, Armonk, NY, USA).

\section{Author contributions}

Guarantor of integrity of entire study, study concepts and design, literature research, manuscript preparation, and manuscript definition of intellectual content; M.H. Clinical studies, data acquisition and analysis/ interpretation, manuscript editing, revision/review, and final version approval; all authors.

\section{CONFLICTS OF INTEREST}

None of the authors have any actual or potential conflicts of interest to declare.

\section{FUNDING}

There were no sources of support for this study.

\section{REFERENCES}

1. World Health Organization. GLOBOCAN 2012: estimated incidence, mortality and prevalence worldwide in 2012. Cervical cancer, http://globocan.iarc.fr/Pages/fact_sheets cancer.aspx.

2. World Health Organization. Sexual and reproductive health. Comprehensive cervical cancer prevention and control-a healthier future for girls and women. WHO guidance note, http://apps.who.int/iris/ bitstream/10665/78128/3/9789241505147_eng.pdf.

3. FIGO Committee on Gynecologic Oncology. FIGO staging for carcinoma of the vulva, cervix, and corpus uteri. Int J Gynaecol Obstet. 2014; 125:97-98.

4. Quinn MA, Benedet JL, Odicino F, Maisonneuve P, Beller U, Creasman WT, Heintz AP, Ngan HY, Pecorelli S. Carcinoma of the cervix uteri. FIGO 26th Annual Report on the Results of Treatment in Gynecological Cancer. Int J Gynaecol Obstet. 2006; 95 Suppl 1:S43-S103.

5. Viswanathan AN, Beriwal S, De Los Santos JF, Demanes DJ, Gaffney D, Hansen J, Jones E, Kirisits C, Thomadsen B, Erickson B. American Brachytherapy Society consensus guidelines for locally advanced carcinoma of the cervix. Part II: high-dose-rate brachytherapy. Brachytherapy. 2012; 11:47-52.

6. Toita T. Current status and perspectives of brachytherapy for cervical cancer. Int J Clin Oncol. 2009; 14:25-30.

7. Sakata K, Sakurai H, Suzuki Y, Katoh S, Ohno T, Toita T, Kataoka M, Tanaka E, Kaneyasu Y, Uno T, Harima Y, Nakano T. Results of concomitant chemoradiation for cervical cancer using high dose rate intracavitary brachytherapy: study of JROSG (Japan Radiation Oncology Study Group). Acta Oncol. 2008; 47:434-441.

8. Wakatsuki M, Kato S, Kiyohara H, Ohno T, Karasawa K, Tamaki T, Ando K, Shiba S, Kamada T, Nakano T. The 
prognostic value of rectal invasion for stage IVA uterine cervical cancer treated with radiation therapy. BMC Cancer. 2016; 16:244.

9. Murakami N, Kasamatsu T, Morota M, Sumi M, Inaba $\mathrm{K}$, Ito Y, Itami J. Radiation therapy for stage IVA cervical cancer. Anticancer Res. 2013; 33:4989-4994.

10. Landoni F, Maneo A, Colombo A, Placa F, Milani R, Perego P, Favini G, Ferri L, Mangioni C. Randomised study of radical surgery versus radiotherapy for stage Ib-IIa cervical cancer. Lancet. 1997; 350:535-540.

11. Perez CA, Grigsby PW, Chao KS, Mutch DG, Lockett MA. Tumor size, irradiation dose, and long-term outcome of carcinoma of uterine cervix. Int J Radiat Oncol Biol Phys. 1998; 41:307-317.

12. Kapp KS, Stuecklschweiger GF, Kapp DS, Poschauko J, Pickel H, Lahousen M, Hackl A. Prognostic factors in patients with carcinoma of the uterine cervix treated with external beam irradiation and IR-192 high-doserate brachytherapy. Int J Radiat Oncol Biol Phys. 1998; 42:531-540.

13. Bae HS, Kim YJ, Lim MC, Seo SS, Park SY, Kang S, Kim SH, Kim JY. Predictors of radiation field failure after definitive chemoradiation in patients with locally advanced cervical cancer. Int J Gynecol Cancer. 2016; 26:737-742.

14. Eifel PJ, Winter K, Morris M, Levenback C, Grigsby PW, Cooper J, Rotman M, Gershenson D, Mutch DG. Pelvic irradiation with concurrent chemotherapy versus pelvic and para-aortic irradiation for high-risk cervical cancer: an update of radiation therapy oncology group trial (RTOG) 90-01. J Clin Oncol. 2004; 22:872-880.

15. Whitney CW, Sause W, Bundy BN, Malfetano JH, Hannigan EV, Fowler WC Jr, Clarke-Pearson DL, Liao SY. Randomized comparison of fluorouracil plus cisplatin versus hydroxyurea as an adjunct to radiation therapy in stage IIB-IVA carcinoma of the cervix with negative paraaortic lymph nodes: a Gynecologic Oncology Group and Southwest Oncology Group study. J Clin Oncol. 1999; 17:1339-1348.

16. Fagundes H, Perez CA, Grigsby PW, Lockett MA. Distant metastases after irradiation alone in carcinoma of the uterine cervix. Int J Radiat Oncol Biol Phys. 1992; 24:197-204.

17. Hata M, Koike I, Miyagi E, Numazaki R, Asai-Sato M, Kasuya T, Kaizu H, Matsui T, Hirahara F, Inoue T. Radiation therapy for very elderly patients aged 80 years and older with squamous cell carcinoma of the uterine cervix. Am J Clin Oncol. 2017; 40:178-182.

18. Rose PG, Ali S, Whitney CW, Lanciano R, Stehman FB. Outcome of stage IVA cervical cancer patients with disease limited to the pelvis in the era of chemoradiation: a Gynecologic Oncology Group study. Gynecol Oncol. 2011; 121:542-545.

19. Biewenga P, Mutsaerts MA, Stalpers LJ, Buist MR, Schilthuis MS, van der Velden J. Can we predict vesicovaginal or rectovaginal fistula formation in patients with stage IVA cervical cancer? Int J Gynecol Cancer. 2010; 20:471-475.

20. Kramer C, Peschel RE, Goldberg N, Kohorn EI, Chambers JT, Chambers SK, Schwartz PE. Radiation treatment of FIGO stage IVA carcinoma of the cervix. Gynecol Oncol. 1989; 32:323-326.

21. NCCN clinical practice guidelines in oncology. Cervical cancer. Version 1. 2017, http://www.tri-kobe.org/nccn/ guideline/gynecological/english/cervical.pdf.

22. National Cancer Institute. Cervical cancer. Cervical cancer treatment, http://www.cancer.gov/cancertopics/pdq/ treatment/cervical/HealthProfessional.

23. Vale C, Tierney JF, Stewart LA, Brady M, Dinshaw K, Jakobsen A, Parmar MK, Thomas G, Trimble T, Alberts DS, Chen H, Cikaric S, Eifel PJ, et al. Reducing uncertainties about the effects of chemoradiotherapy for cervical cancer: a systematic review and meta-analysis of individual patient data from 18 randomized trials. J Clin Oncol. 2008; 26:5802-5812.

24. Mabuchi S, Isohashi F, Okazawa M, Kitada F, Maruoka S, Ogawa K, Kimura T. Chemoradiotherapy followed by consolidation chemotherapy involving paclitaxel and carboplatin and in FIGO stage IIIB/IVA cervical cancer patients. J Gynecol Oncol. 2017; 28:e15.

25. Pearcey R, Brundage M, Drouin P, Jeffrey J, Johnston D, Lukka H, MacLean G, Souhami L, Stuart G, Tu D. Phase III trial comparing radical radiotherapy with and without cisplatin chemotherapy in patients with advanced squamous cell cancer of the cervix. J Clin Oncol. 2002; 20:966-972.

26. Datta NR, Stutz E, Liu M, Rogers S, Klingbiel D, Siebenhüner A, Singh S, Bodis S. Concurrent chemoradiotherapy vs. radiotherapy alone in locally advanced cervix cancer: a systematic review and metaanalysis. Gynecol Oncol. 2017; 145:374-385.

27. Moore KN, Gold MA, McMeekin DS, Zorn KK. Vesicovaginal fistula formation in patients with stage IVA cervical carcinoma. Gynecol Oncol. 2007; 106:498-501.

28. Tsushima T, Mizusawa J, Sudo K, Honma Y, Kato K, Igaki H, Tsubosa Y, Shinoda M, Nakamura K, Fukuda H, Kitagawa Y. Risk factors for esophageal fistula associated with chemoradiotherapy for locally advanced unresectable esophageal cancer: a supplementary analysis of JCOG0303. Medicine (Baltimore). 2016; 95:e3699.

29. Taniguchi H, Yamazaki K, Boku N, Funakoshi T, Hamauchi S, Tsushima T, Todaka A, Sakamoto T, Tomita H, Machida N, Taku K, Fukutomi A, Onozawa Y, et al. Risk factors and clinical courses of chemoradiation-related arterioesophageal fistula in esophageal cancer patients with clinical invasion of the aorta. Int J Clin Oncol. 2011; 16:359-365.

30. Satake H, Tahara M, Mochizuki S, Kato K, Hara H, Yokota T, Kiyota N, Kii T, Chin K, Zenda S, Kojima T, Bando H, 
Yamazaki T, et al. A prospective, multicenter phase I/II study of induction chemotherapy with docetaxel, cisplatin and fluorouracil (DCF) followed by chemoradiotherapy in patients with unresectable locally advanced esophageal carcinoma. Cancer Chemother Pharmacol. 2016; 78:91-99.

31. Sobin LH, Gospodarowicz MK, Wittekind C. TNM classification of malignant tumours. 7th ed. Hoboken: Wiley-Blackwell, 2010.

32. Withers HR, Thames HD Jr, Peters LJ. A new isoeffect curve for change in dose per fraction. Radiother Oncol. 1983; 1:187-191.
33. Tod MC, Meredith WJ. A dosage system for use in the treatment of cancer of the uterine cervix. Br J Radiol. 1938; 11:809-824.

34. Cox JD, Stetz J, Pajak TF. Toxicity criteria of the Radiation Therapy Oncology Group (RTOG) and the European Organization for Research and Treatment of Cancer (EORTC). Int J Radiat Oncol Biol Phys. 1995; 31:1341-1346.

35. Kaplan EL, Meier P. Nonparametric estimation from incomplete observations. J Am Stat Assoc. 1958; 53:457-481. 